\title{
Comparison of Fault Detection Techniques for Induction Motors
}

\author{
Amir Ahmed Qazi \\ Mechatronics Engineering \\ IICT, MUET, Jamshoro \\ Sindh, Pakistan
}

\author{
Jawaid Daudpoto, PhD \\ Mechatronics Engineering \\ IICT, MUET, Jamshoro \\ Sindh, Pakistan
}

\author{
Salman Ahmed Shaikh \\ Mechatronics Engineering \\ IICT, MUET, Jamshoro \\ Sindh, Pakistan
}

\begin{abstract}
In the era of twenty-first century, induction motor plays a dominant role in industrial processes and essentially run out 40 to $50 \%$ of total energy demand. Accordingly, their safety, durability, and efficiency are of major concern. Faults developing in induction motor necessitates significant consideration as they eradicate its operation and reduce the mean life. In this research, the most widely used MCSA that captures stator current signatures and acceleration-based vibration diagnosis techniques are practically investigated employing low-cost sensors. Moreover,the comparative analysis is performed to find an effective method for detection of faults, efficiently and persuade motor safety and reliable operation.
\end{abstract}

\section{General Terms}

Condition Monitoring of Induction Motor.

\section{Keywords}

Motor Current Signature Analysis (MSCA), Fast Fourier Transform (FFT), Condition Monitoring (CM).

\section{INTRODUCTION}

With the escalating evolution in industrial processes, IMs have replaced $90 \%$ of the actuators altogether exercised in the production line and were surveyed to be more faulttolerant $[1,2]$. Pre-diagnosis of faults occurring in induction motors can increase, its durability. In consequence, the practical investigation is crucial to execute condition monitoring techniques of an IM.

Manufacturing imperfections, installation, maintenance schedule, and inadequate lubrication are the reported factors of faults in IMs [3]. The engineers are confronting challenges for providing adequate protection to electric motors. Origin of failures in IMs bifurcated as internal and external and subdivided into electrical, environmental, and mechanical defects in Fig.1.

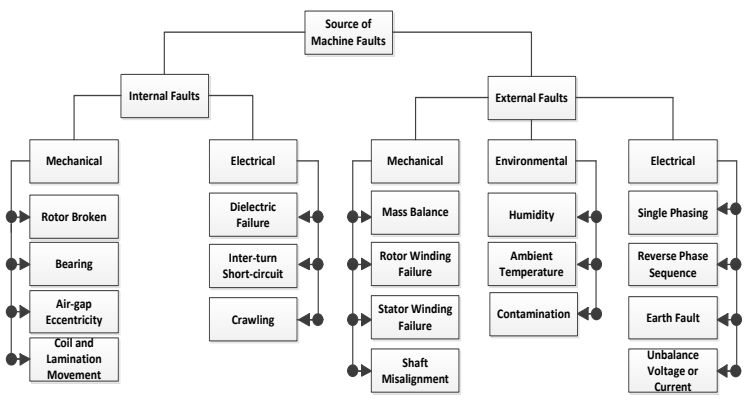

Fig1:Faults classification in IM
Numerous types of faults along with their sources are tabulated in Table 1.

Table I. Faults and their causes in IM

\begin{tabular}{|c|l|}
\hline Fault & \multicolumn{1}{|c|}{ Causes } \\
\hline Bearing & $\begin{array}{l}\text { Fabrication } \\
\text { Inappropriate oiling, debris due to } \\
\text { friction }\end{array}$ \\
\hline $\begin{array}{c}\text { Rotor } \\
\text { Misalignment }\end{array}$ & $\begin{array}{l}\text { Untrue coupling, inadequate } \\
\text { installation, deterioration of bearing, } \\
\text { overload }\end{array}$ \\
\hline $\begin{array}{c}\text { Air gap } \\
\text { Eccentricity }\end{array}$ & $\begin{array}{l}\text { Irregular magnetic pull, rotor } \\
\text { misalignment, bearing defects }\end{array}$ \\
\hline $\begin{array}{c}\text { Broken Bars } \\
\text { (rotor) }\end{array}$ & $\begin{array}{l}\text { Considerable transient, thermic stress, } \\
\text { Fabrication faults, Unbalance magnetic } \\
\text { pull, negative sequence in supply, }\end{array}$ \\
\hline $\begin{array}{c}\text { Stator } \\
\text { Winding }\end{array}$ & $\begin{array}{l}\text { Installation deficiency, Supply Surges, } \\
\text { lessen of coil }\end{array}$ \\
\hline
\end{tabular}

ASEA Brown Boveri (ABB), Electric Power Research Institute (EPRI), and Institution of Electrical and Electronic Engineers (IEEE) carried out studies on faults occurring in motors as shown in Table 2.

Table 2. Statistics of IM faults

\begin{tabular}{|l|c|c|c|}
\hline \multirow{2}{*}{\multicolumn{1}{|c|}{ Faults }} & \multicolumn{3}{|c|}{ Percentage of Occurrence (\%) } \\
\cline { 2 - 4 } & ABB & EPRI & IEEE \\
\hline Shaft coupling & 2 & & \\
\hline Stator & 16 & 28 & 36 \\
\hline Rotor bar & 5 & 9 & 8 \\
\hline Bearing & 51 & 41 & 42 \\
\hline Other & 10 & 22 & 14 \\
\hline External conditions & 16 & & \\
\hline
\end{tabular}

Several CM techniques are reported in the literature. Online $\mathrm{CM}$ for double cage rotor [4], bearing and stator winding faults frequently encountered in $\operatorname{IM}[5,6]$, acoustic emissions and vibration-based CM [7-8], bearing faults and diagnostic methods are outlined in $[9,10]$. In [11] and [12], bearing fault was detected using vibrations and stator current respectively. The image-based algorithm for allocation of faults with different classifiers presented in [13], [14] discussed IRT-based thermal image segmentation to recognize end rings and broken rotor problems. In [15], authors have reviewed fault detection techniques to identify broken rotor bar faults in IM. A review divulged to identify eccentricity problems [16]. In [17], the author addressed vibration analysis based on 
DWT for the identification of rotor incipient broken bar faults. Acoustic emission integrating with vibration signals are discussed to properly point out the failure in IM [18]. It is proposed to use MCSA for achieving better reliability of operation of IM $[19,20]$. Researchers have used thermal images to identify the roller-bearing fault in IM [21, 22]. $\mathrm{CM}$ techniques are mapped against faults in Table 3.

Table3. IMs faults mapping with monitoring techniques

\begin{tabular}{|c|c|c|c|c|}
\hline Fault & MCSA & $\begin{array}{c}\text { Vibration } \\
\text { Analysis }\end{array}$ & $\begin{array}{c}\text { Temperature } \\
\text { Monitoring }\end{array}$ & $\begin{array}{c}\text { Acoustic } \\
\text { Emission }\end{array}$ \\
\hline Bearing & $\checkmark$ & $\checkmark$ & $\checkmark$ & $\checkmark$ \\
\hline Inter-turn & & $\checkmark$ & $\checkmark$ & \\
\hline Broken Rotor & $\checkmark$ & $\checkmark$ & $\checkmark$ & \\
\hline $\begin{array}{c}\text { Air gap } \\
\text { Eccentricity }\end{array}$ & $\checkmark$ & & & \\
\hline $\begin{array}{c}\text { Mass } \\
\text { Misalignmen } \\
\text { t }\end{array}$ & $\checkmark$ & & $\checkmark$ & \\
\hline $\begin{array}{c}\text { Mass } \\
\text { Unbalance }\end{array}$ & & & & \\
\hline
\end{tabular}

Comparative analysis has shown, Motor Square Current Signature Analysis (MSCSA) provides significant signatures among Principle Component Analysis (PCA) and MCSA techniques to identify broken rotor bars faults [23]. Current signature-based approaches are compared to diagnose gearbox faults [24]. Researchers have investigated different measurement techniques to determine the bearing faults [25]. In [26], authors have presented a review on machine learning algorithms-based fault detection techniques for IM. MCSA is reported to be an effective method for electrical fault detection in IM [27].

Although authors have presented various studies in literature, despite that very few work published relative analysis among MCSA and accelerometer-based vibration analysis for revealing faults of a squirrel cage IM. In this research, MCSA and vibration analysis techniques are experimentally investigated to find an efficient method to identify fault developing in squirrel cage IM.

In this paper introduction \& related studies reported in the literature are presented in Section I. Section II includes methodology adopted for the implementation of MSCA and vibration technique. Experimental results are shown in Section III. Section IV deals with the conclusion made from acquired results. Furthermore, future recommendations summarized the research paper in Section V.

\section{MATERIAL \& METHODS}

Thephysical system is divided into two parts. At first,the dedicated setup has been developed to characterize both current and vibration sensors. In the second phase sensors are interfaced with the arduino mega 2560 controller to acquire serial data, which is processed to properly diagnose the health of IM.

The circuit diagrams, in Fig. 2 and Fig. 4 were implemented to calibrate the current sensor and accelerometer respectively. Hall effect based current sensor module has very low input impedance thus an external resistor of value 32R 2 ohms were connected in series to limit the current in safe operating range. A set of voltages were applied at input circuit of current sensor and resulting output in millivolts was serially monitored using arduino microcontroller to find equation relating input current and output voltage.

In Fig.3, the output voltage of current sensor is plotted against the input current flowing through the load and internal resistance of the current sensor. The statistical value of $R^{2}$ relates the dependent and independent variable using a regression line. $\mathrm{R}$ square value closer to unity shows strong relationship $b / w$ the data points and linear trend line.

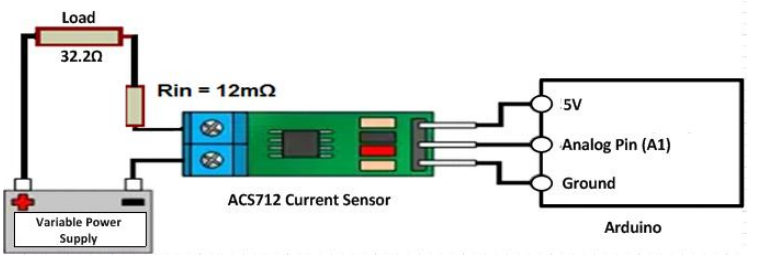

Fig 2: Current sensor characterization circuit

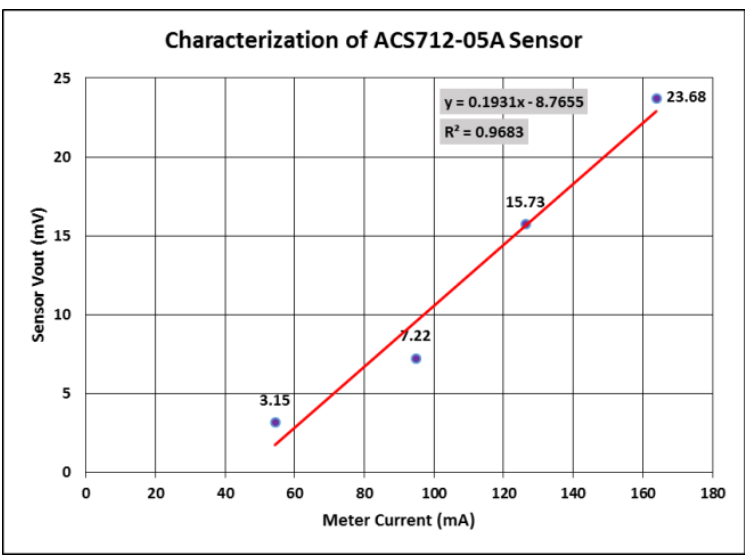

Fig 3: Characteristic curve of ACS712 current sensor

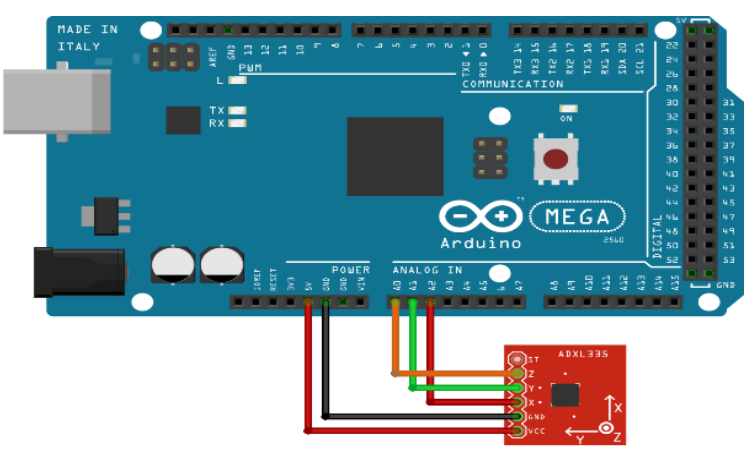

Fig 4: Interfacing of adxl335 with arduinomega2560

Furthermore, the practical setup for accelerometer characterization was developedas shown in Fig.5. The test setup were comprises of sensor block and calibrated scale block. The accelerometer was successively characterized in both $\mathrm{x}$ and y direction as delineated in Fig.6 and Fig.7 respectively.At first, accelerometer was placed on sensor block to measure the value of $\mathrm{g}$ in $\mathrm{x}$ direction while $\mathrm{y}$ and $\mathrm{z}$ remains constant. The sensor block was rotated in steps of 5 degrees over a calibrated scale block. The value of $\mathrm{g}$ in $\mathrm{x}$ direction saturates after 75 degrees as shown in Fig.6. Secondly, the adxl345 was attached on sensor block in y direction taking $\mathrm{x}$ and $\mathrm{z}$ axis values of $\mathrm{g}$ constant and 
minor changes was detected in value of $g$ after 75 degrees of rotation of sensor block. The regression line have been drawn as displayed in Fig.6, initially till the first ten degrees the value of $\mathrm{g}$ deviates from the trend line, thus do not follow linear relation,the data points from 15 to 65 degrees obeys linearity whereas g gets saturatedafter 75 degree of rotation.

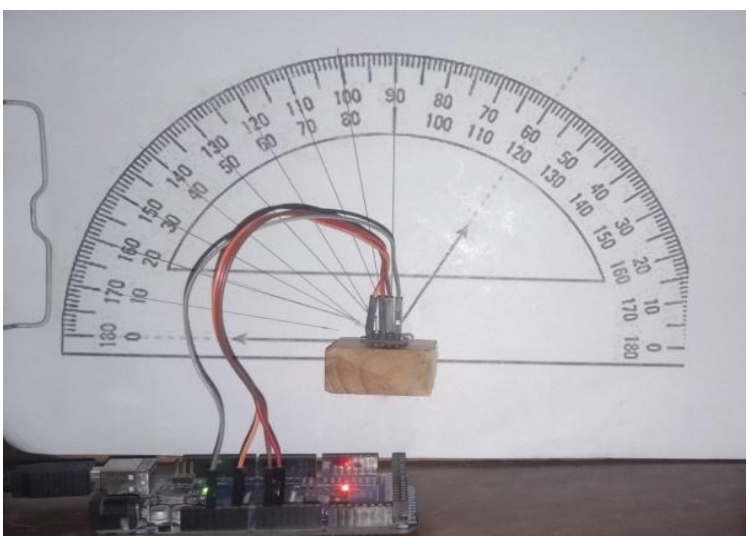

Fig 5: Adxl335 characterization system

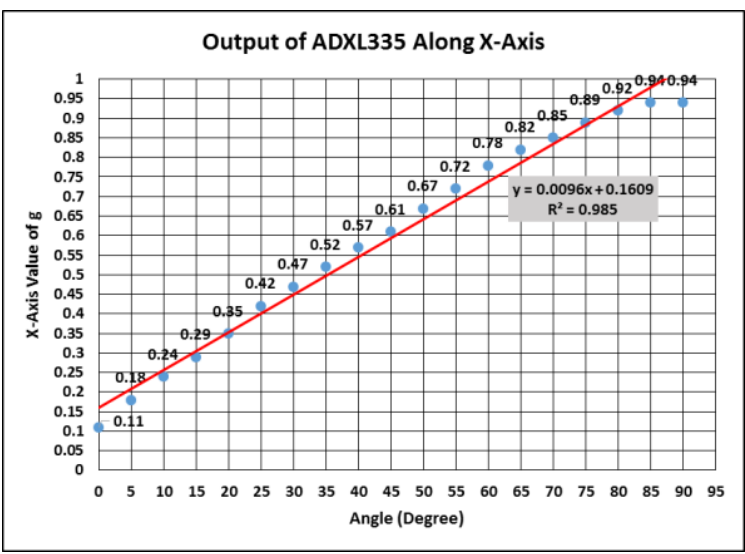

Fig 6: Characterization of Adxl335 along x-axis

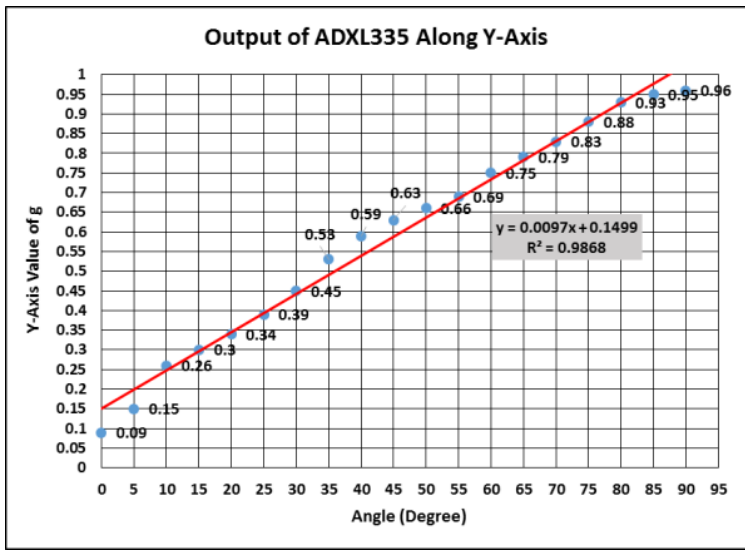

Fig 7: Characterization of Adxl335 along y-axis

The statistical line was drawn as seen in Fig.7; at first, the value of $\mathrm{g}$ differs significantly from the trend line until the first 5 degrees, hence the data sets do not follow strong correlation; however, the statistics point from 10 to 30 degrees comply strong linearity, whereas g diverges from the regression line again between 35 and 50 degree and becomes saturated after 75 degrees of rotation. After characterization, both the current sensor and the accelerometer are used to implement MCSA and vibration analysis techniques for IM health detection. The proposed system's block diagram is shown in Fig.8.

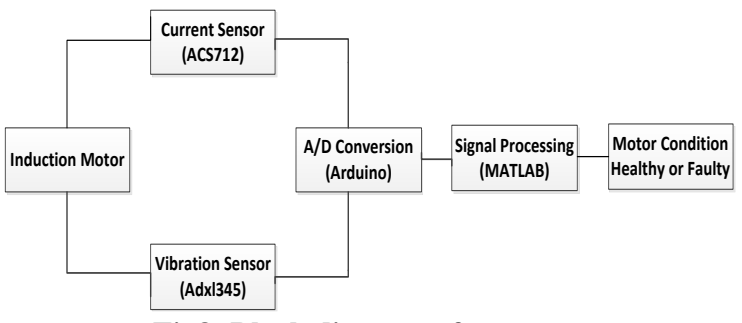

Fig8: Block diagram of test setup

\subsection{Motor Current Signature Analysis}

The stator current of IM is accomplished employing ACS712-05B-T sensor and digitized using arduino microcontroller ADC. Subsequently, the finite number of current samples were transmitted serially and analyzed using the FFT tool in MATLAB. Besides the fundamental harmonic at $50 \mathrm{~Hz}$ supply frequency) all leftover frequencies in the stator current reflect the unhealthy condition of an induction motor.

\subsection{Vibration Analysis}

MEMS-based tri-axis Adxl335-accelerometer was utilized for vibration measurement. Arduino controller provides the mean for $\mathrm{ADC}$ conversion of vibration data that in pursuit transmitted over serial port to perform FFT n MATLAB. The spectrum of serial data was acquired in both healthy and faulty conditions of IMs at low, medium, and high speed respectively. The newly developed frequency components the FFT of vibration data identify the faulty condition of an IM.

\section{RESULTS \& DISCUSSIONS}

Due to timely degradation of motor performance, the difference in speed between new and old IM may also appear at even no or light loads. MCSA and accelerometer-based fault diagnosis techniques were investigated at scenarios listed in Table 4.

Table 4. Experimental Design

\begin{tabular}{|c|c|c|c|}
\hline Method & Scenarios \# & Speed & $\begin{array}{c}\text { Motor } \\
(125 \text { W) }\end{array}$ \\
\hline \multirow{6}{*}{ MCSA } & \multirow{2}{*}{1} & \multirow{2}{*}{ Low } & New \\
\hline & & & Old \\
\hline & \multirow{2}{*}{2} & \multirow{2}{*}{ Medium } & New \\
\hline & & & Old \\
\hline & \multirow{2}{*}{3} & \multirow{2}{*}{ High } & New \\
\hline & & & Old \\
\hline \multirow{6}{*}{$\begin{array}{l}\text { Accelerometer } \\
\text { (X-Axis) }\end{array}$} & \multirow{2}{*}{4} & \multirow{2}{*}{ Low } & New \\
\hline & & & Old \\
\hline & \multirow{2}{*}{5} & \multirow{2}{*}{ Medium } & New \\
\hline & & & Old \\
\hline & \multirow{2}{*}{6} & \multirow{2}{*}{ High } & New \\
\hline & & & Old \\
\hline \multirow{6}{*}{$\begin{array}{l}\text { Accelerometer } \\
\text { (Y-Axis) }\end{array}$} & \multirow{2}{*}{7} & \multirow{2}{*}{ Low } & New \\
\hline & & & Old \\
\hline & \multirow{2}{*}{8} & \multirow{2}{*}{ Medium } & New \\
\hline & & & Old \\
\hline & \multirow{2}{*}{9} & \multirow{2}{*}{ High } & New \\
\hline & & & Old \\
\hline
\end{tabular}


In Fig.9, Fig.10, and Fig.11 significant bands resulting from FFT of stator current of both motors at speed of approximately 490, 980 and 1072 rpms is plotted.

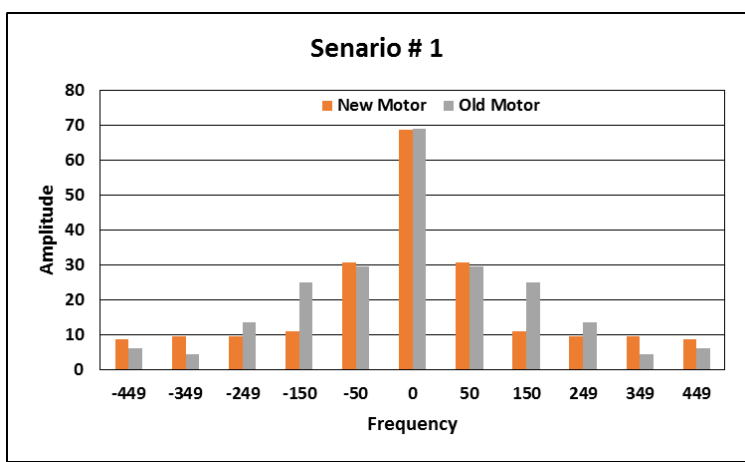

Fig9: Comparison of FFT of both motors using MCSA at low speed

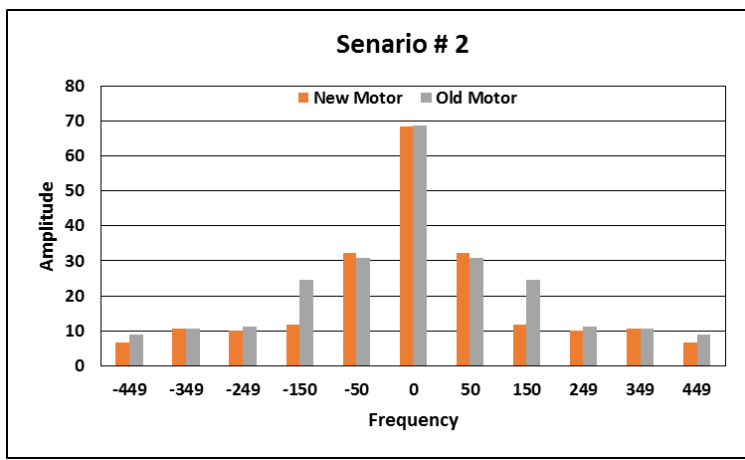

Fig10: Comparison of FFT of both motors using MCSA at medium speed

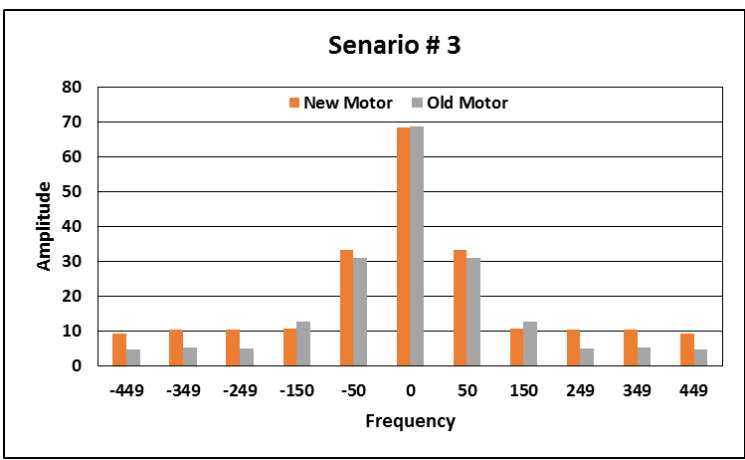

Fig11: Comparison of FFT of both motors using MCSA high speed

Table.5 summarizes the data collected using MCSA at both new and old motors. It can be deduced from the listed data that both IMs produce various frequency components that are multiples of the fundamental frequency $(50 \mathrm{~Hz})$, but the amplitudes of harmonics produced in the old motor at $150,249,349$, and 449 are significantly larger than those produced in the new IM, which in result depicts the faulty condition of and old IM.
Table 5.Comparison of MSCA data for both new and old motor

\begin{tabular}{|c|c|c|c|c|c|c|}
\hline \multicolumn{7}{|c|}{ MCSA } \\
\hline \multirow{2}{*}{ 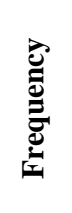 } & \multicolumn{2}{|c|}{ Low Speed } & \multicolumn{2}{|c|}{$\begin{array}{l}\text { Medium } \\
\text { Speed }\end{array}$} & \multicolumn{2}{|c|}{ High Speed } \\
\hline & 总节 & 흥 & 总高 & $\bar{\partial}$ & 总竞 & 흥 \\
\hline-449 & 8.67 & 6.25 & 6.47 & 8.99 & 9.42 & 4.73 \\
\hline-349 & 9.51 & 4.31 & 10.44 & 10.48 & 10.6 & 5.51 \\
\hline-249 & 9.5 & 13.6 & 9.87 & 11.07 & 10.4 & 4.96 \\
\hline-150 & 11.06 & 25 & 11.83 & 24.68 & 10.9 & 12.7 \\
\hline-50 & 30.66 & 29.6 & 32.25 & 30.74 & 33.4 & 31.1 \\
\hline 0 & 68.62 & 68.9 & 68.51 & 68.81 & 68.5 & 68.8 \\
\hline 50 & 30.66 & 29.6 & 32.25 & 30.74 & 33.4 & 31.1 \\
\hline 150 & 11.06 & 25 & 11.83 & 24.68 & 10.9 & 12.7 \\
\hline 249 & 9.5 & 13.6 & 9.87 & 11.07 & 10.4 & 4.96 \\
\hline 349 & 9.51 & 4.31 & 10.44 & 10.48 & 10.6 & 5.51 \\
\hline 449 & 8.67 & 6.25 & 6.47 & 8.99 & 9.42 & 4.73 \\
\hline
\end{tabular}

The results accomplished, affirms the healthy condition of the new motor as no sidebands with distinct amplitudes are produced except at dc level and fundamental component at $50 \mathrm{~Hz}$, unlike the case of an old motor. Comparison of vibration data collected at three discussed speeds along the $\mathrm{x}$-axis is shown in Fig.12, Fig.13, and Fig.14. Various distinct frequencies at 33 and $58 \mathrm{~Hz}$, along with the significant change in amplitude of some components at 8 , 42, 50, 67, 100 and $141 \mathrm{~Hz}$ observed in Fig. 12. The discrepancy in characteristics of experimental outcomes evidenced distinct conditions of both motors.

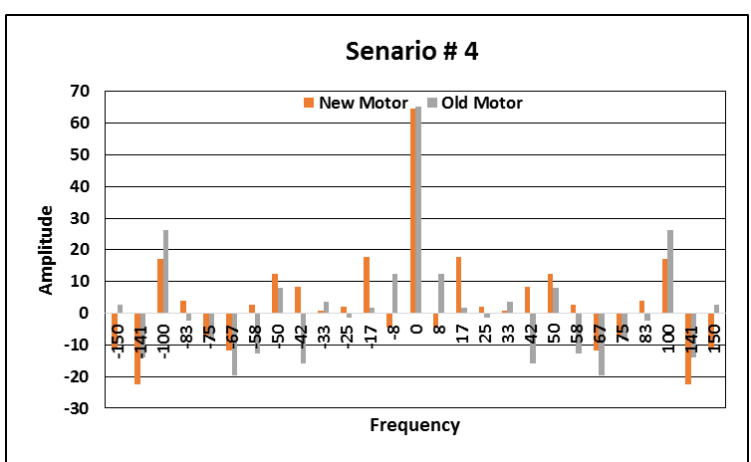

Fig12: Comparison of vibrations along the $x$-axis of both motors at low speed

Furthermore, Fig.13 and Fig.14 unveiled the dissimilar state of IMs both together, highlighting the conflicting harmonics at 33, 50, 83, and $67 \mathrm{~Hz}$, whereas the remarkable change can also be observed in co-efficient of $100 \mathrm{~Hz}$ and $17,25,58,100 \mathrm{~Hz}$ respectively. 


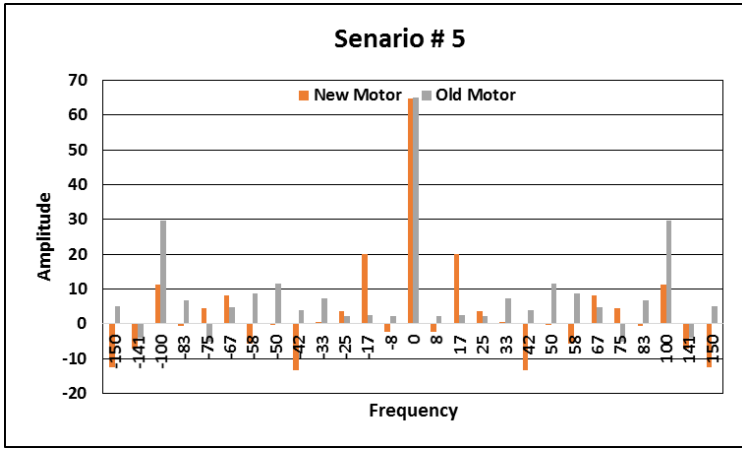

Fig13: Comparison of vibrations along $x$-axis of both motors at medium speed

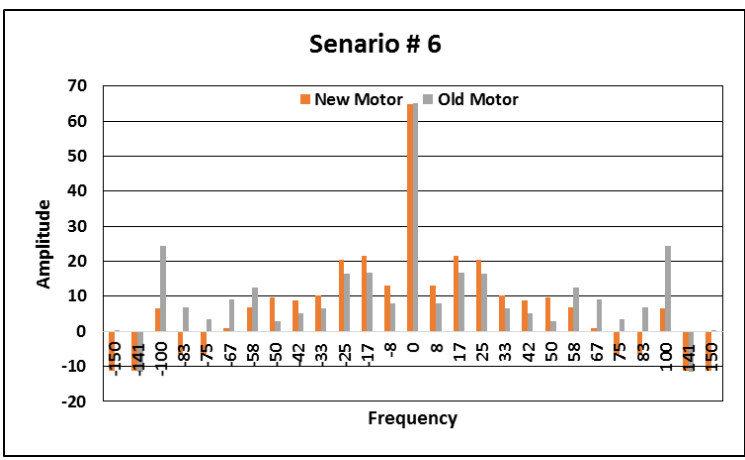

Fig14: Comparison of vibrations along the $x$-axis of both motors at high speed

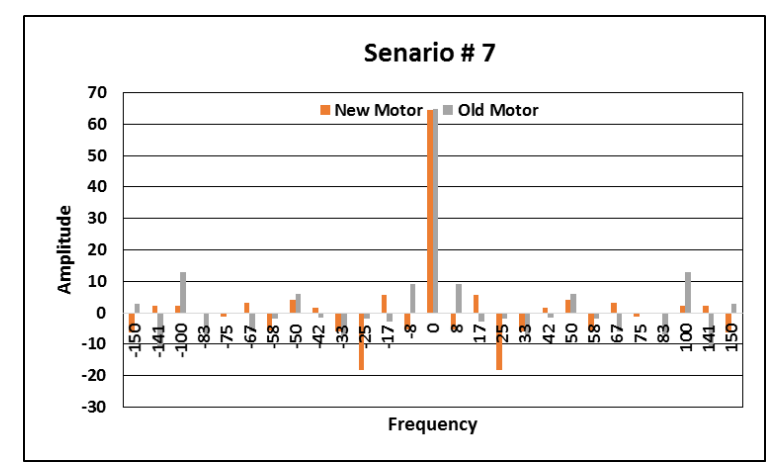

Fig15: Comparison of vibrations along $y$-axis of both motors at low speed

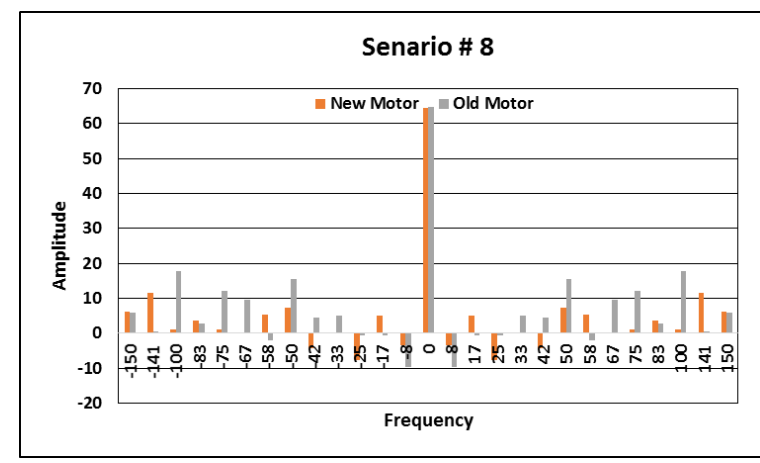

Fig16: Comparison of vibrations along $y$-axis of both motors at medium speed

Subsequently, the analogy between the outcomes of vibrations produced along the $y$-axis of accelerometer mounted on either motor was evaluated as shown in Fig.15, Fig.16, and Fig.17. The comparative investigation has conceivably differentiated among conditions of both motors.

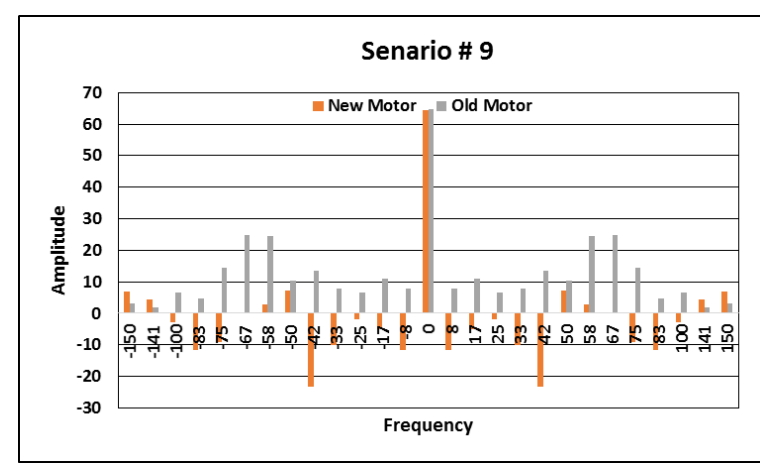

Fig17: Comparison of vibrations along $y$-axis of both motors at high speed

\section{CONCLUSION}

This research employed low-cost sensors for the implementation of both MCSA and vibration analysis techniques for tracking the condition of electric motors. Both techniques were examined on numerous scenarios where acquired results have shown notabledifferences among FFT of new and old motor data at low medium and high speed.

The experimental data of old motor acquired using MCSA, evident the presence of odd harmonics with significant amplitudes at low, medium, and high speed. Unlike MCSA the change in amplitudes of harmonics at $8,17,25,33,50$, $58,67,75$, and $100 \mathrm{~Hz}$ measured along $\mathrm{x}$ and the y axis of accelerometer can be observed from the FFT of an old motor to the new motor which depicts the faulty condition of old IM.

Ithas been derived from the above experiments that MCSA produces distinguishable frequency components evenly spaced by the fundamental frequency of ac supply and no dedicated placement of the current sensor is required whereas sophisticated placement of sensor required in case of accelerometer-based approach and non-uniform pattern of harmonics produced with lessor amplitudes in contrast to sidebands frequencies developed in MCSA. Consequently, comparative analysis has shown MSCA to be a better approach for diagnosing and condition monitoring of an IM.

MCSA and vibration methods were correlated and analysis unveiled MCSA to be more apparent as noticeable differences were observed in harmonic components of current and vibration data of old motor.

\section{FUTURE RECOMMENDATION}

In the proposed research, the health of single-phase IMs was investigated at no load condition whereas the same scenarios can be developed at various load conditions that will change the slip of an induction motor and hence results.Moreover, research can also be extended to diagnose fault using the integration of both MCSA and accelerometer techniques.

Furthermore, the FFT tool was only considered, while discrete wavelet transform and other neural network algorithms can be employed and comparative study can be proposed. Also, the proposed topology was not aimed to detect any particular faults rather research context was general. The Relative study can be carried out to monitor 
both electrical and mechanical faults and find the most apparent method for proper health monitoring of IM.

\section{ACKNOWLEDGMENTS}

I, Amir Ahmed Qazi, acknowledge Mehran University of Engineering \& Technology Jamshoro for providing all lab facilities and guidance from recognized faulty members during my research work.

\section{REFERENCES}

[1] Nunez J, Velazquez L, Hernandez L, Troncoso R, Osornio-Rios R, "Low-cost thermographic analysis for bearing fault detection on induction motors", Journal of Science and Industrial Research, (2016). 75:412-415.

[2] Gangsar, P., \& Tiwari, R, "Comparative investigation of vibration and current monitoring for prediction of mechanical and electrical faults in induction motor based on multiclass-support vector machine algorithms", Mechanical Systems and Signal Processing (Elsevier), (2017). 94, 464-481.

[3] Hadden, T., Jiang, J. W., Bilgin, B., Yinye Yang, Sathyan, A., Dadkhah, H., \&Emadi, A, "A Review of Shaft Voltages and Bearing Currents in EV and HEV Motors", IECON 2016 - 42nd Annual Conference of the IEEE Industrial Electronics Society.

[4] Hmida, M. A. \& Braham, A, “An on-line condition monitoring system for incipient fault detection in double-cage induction motor", IEEE Transactions on Instrumentation and Measurement, 2018. 67, 18501858 .

[5] Glowacz, A., Glowacz, W., Glowacz, Z., \&Kozik, J, "Early fault diagnosis of bearing and stator faults of the single-phase induction motor using acoustic signals", Measurement (Elsevier), 2018. 113, 1-9.

[6] Dash, R. N., Sahu, S., Panigrahi, C. K., \&Subudhi, B, "Condition monitoring of induction motors: - A review", 2016 International Conference on Signal Processing, Communication, Power and Embedded System (SCOPES), 2016.

[7] Othman MS, Nuawi MZ, Mohamed R, "Experimental comparison of vibration and acoustic emission signal analysis using kurtosis-based methods for induction motor bearing condition monitoring", PrzegladElektrotechniczny, 2016. 92(11):208-212.

[8] Othman MS, Nuawi MZ, Mohamed R, "Vibration and acoustic emission signal monitoring for detection of induction motor bearing fault", International Journal of Engineering Research \& Technology (IJERT), 2015. 4(5).

[9] Duan, Z., Wu, T., Guo, S., Shao, T., Malekian, R., \& $\mathrm{Li}, \mathrm{Z}$, "Development and trend of condition monitoring and fault diagnosis of multi-sensors information fusion for rolling bearings: a review", The International Journal of Advanced Manufacturing Technology, 2018. 96, 803-819.

[10] Malla, C., \&Panigrahi, I, "Review of Condition Monitoring of Rolling Element Bearing Using Vibration Analysis and Other Technique", Journal of Vibration Engineering \& Technologies (Springer), 2019. 7, 407-414.
[11] MisraR., Shinghal K., Saxena A., Agarwal A, "Industrial Motor Bearing Fault Detection Using Vibration Analysis", International Conference on Intelligent Computing and Smart Communication 2019. Algorithms for Intelligent Systems. Springer, Singapore, 2020. 827-839.

[12] Singh, S., \& Kumar, N, "Detection of Bearing Faults in Mechanical Systems Using Stator Current Monitoring”, IEEE Transactions on Industrial Informatics, 2016. 13(3), 1341-1349.

[13] Mousavi S, Kar NC, Timusk M, "A novel parallel modelling-wavelet based mechanical fault detection using stator current signature of induction machine under variable load conditions", Journal of Electrical Engineering \& Electronic Technology, (2017). 6(2):2-9.

[14] Glowacz A, Glowacz Z, "Diagnosis of the threephase induction motor using thermal imaging", Infrared Physics \& Technology, (2017). 81:7-16.

[15] Ola E. Hassan, MotazAmer, Ahmed K. Abdelsalam, Barry W. Williams, "Induction motor broken rotor bar fault detection techniques based on fault signature analysis - a review", IET Electric Power Applications, 2018. 12(7), 895 - 907.

[16] Nikhil, Mathew, L., \& Sharma, A, "Various Indices for Diagnosis of Air-gap Eccentricity Fault in Induction Motor-A Review", IOP Conference Series: Materials Science and Engineering, 2017. 331.

[17] Rangel-Magdaleno, J., Peregrina-Barreto, H., Ramirez-Cortes, J., Morales-Caporal, R. \& CruzVega, I, "Vibration analysis of partially damaged rotor bar in induction motor under different load condition using DWT", 2016. Shock and Vibration.

[18] Delgado-Arredondo, P. A., Morinigo-Sotelo, D., Osornio-Rios, R. A., Avina-Cervantes, J. G., RostroGonzalez, H., \& Romero-Troncoso, R. de J, "Methodology for fault detection in induction motors via sound and vibration signals", Mechanical Systems and Signal Processing (Elsevier), (2017). 83, 568589.

[19] Prakasam, K. and Ramesh, S, "Testing and Analysis of Induction Motor Electrical Faults Using Current Signature Analysis", Circuits and Systems, 2016. 7, 2651-2662.

[20] Singhal A, Khandekar MA, "Bearing fault detection in induction motor using motor current signature analysis", Int J Adv Res Electr Electron InstrumEng, 2013. 2(7):3258-3264.

[21] Huo, Z.; Zhang, Y.; Sath, R.; Shu, L, "Self-adaptive fault diagnosis of roller bearings using infrared thermal image", In Proceedings of the 43rd Annual Conference of the IEEE Industrial Electronics Society (IECON 2017), Beijing, China.

[22] A. Widodo and B.-S. Yang, "Support vector machine in machine condition monitoring and fault diagnosis", Mechanical systems and signal processing, 2007. 21(6), 2560-2574.

[23] Pires, V. F., Martins, J., Pires, A. \& Rodrigues, L, "Induction motor broken bar fault detection based on MCSA, MSCSA and PCA: A comparative study", 2016 10th International Conference on Compatibility, 
Power Electronics and Power Engineering (CPEPOWERENG), IEEE, 2016. 298-303.

[24] Jin, X., Cheng, F., Peng, Y., Qiao, W. \&Qu, L, “A comparative study on Vibration-and current-based approaches for drivetrain gearbox fault diagnosis" 2016 IEEE Industry Applications Society Annual Meeting, IEEE, 2016. 1-8.

[25] Mitra, S. \&Koley, C, "Different measurement techniques for detection of bearing faults in industrial actuators - comparative study" 2017 IEEE Calcutta Conference (CALCON), IEEE, 2017. 412-417.

[26] Kumar, P., Hati, A.S, "Review on Machine Learning Algorithm Based Fault Detection in Induction Motors". Arch Computat Methods Eng, 2021. 28, 1929-1940.

[27] Gundewar, S.K., Kane, P.V,“Condition Monitoring and Fault Diagnosis of Induction Motor", J. Vib. Eng. Technol, 2021. 9, 643-674. 